\title{
Conclusion
}

\section{Nuclear Revolution or Nuclear Revolutions?}

The theory of nuclear opportunism offers an explanation for the way in which states think about and use nuclear weapons in international politics. Nuclear weapons are useful tools that allow a state to pursue a range of foreign policy goals, and states that acquire nuclear weapons use them in a variety of ways that reflect the differing political priorities and goals that different states have. These political priorities, in turn, reflect the different strategic circumstances that states find themselves in. The evidence from Britain, South Africa, and the United States, as well as the additional cases examined in chapter 5 , largely supports the theory. This chapter summarizes the findings of the book and outlines implications both for our theoretical understanding of nuclear weapons and international politics and for policymakers.

\section{Summary of the Findings}

The small number of cases of nuclear acquisition means that there is inevitably uncertainty regarding the interpretation of individual cases and in the strength of the conclusions we can draw about the way in which nuclear weapons affect the foreign policies of the states that acquire them. This uncertainty is exacerbated by the extent to which statesmen (wisely) seek to maintain secrecy around their nuclear weapons and the strategic goals they hope to achieve with them. Nonetheless, the weight of the evidence examined here supports the theory of nuclear opportunism. The theory of nuclear opportunism performs well (though certainly not perfectly) across the cases, and performs better than the alternative explanations.

In the case of the United Kingdom, from the immediate aftermath of World War II, British elites viewed nuclear weapons as a solution to two fundamental political problems they faced: the problem of dependence on the United 
States, and the problem of maintaining Britain's position in the world despite Britain facing long-run economic (and thus political) decline. Britain therefore found pursuing independence from the United States, bolstering its junior allies, and standing more firmly in the face of challenges to its position to be attractive, and Britain used nuclear weapons to facilitate those behaviors. After acquiring a deliverable nuclear capability in 1955, Britain was able to bolster its allies in Asia, the Middle East, and Europe, and responded to challenges to its position more steadfastly and independently of the preferences of the United States, despite simultaneously cutting back on its conventional forces over the same period. These outcomes are consistent with the predictions of nuclear opportunism for a state in Britain's position: not facing severe territorial threats or involved in a war but constrained by a senior ally and declining in power.

The way in which South African elites thought about and used their nuclear weapons was dramatically different from the way in which the British had done some twenty years earlier. South African elites viewed nuclear weapons as a partial solution to the constraints posed by fears of escalation in South Africa's conduct of the Border War in Angola. South African elites were deeply fearful of escalation and the potential for further Soviet involvement in the conflict, and saw nuclear weapons as a tool that allowed them to reduce those risks. As a result, after acquiring nuclear weapons, South African tolerance for escalation in the Border War increased and South Africa became more willing to act aggressively in the conflict, taking actions that South African elites had previously avoided due to the risk of escalation that they posed. South Africa did not use nuclear weapons to engage in the other foreign policy behaviors that nuclear weapons facilitate, an outcome largely consistent with the theory of nuclear opportunism for a state facing serious threats and involved in an ongoing war.

The United States offers the most complex case, and the one in which the precise predictions of the theory of nuclear opportunism are hardest to validate. In part this is because the enormously complex and changing international environment in the aftermath of World War II makes distinguishing between the different foreign policy behaviors in the typology more challenging than in the other two cases. Even in this case, however, the theory of nuclear opportunism outperforms the alternative explanations. Nuclear acquisition substantially affected US foreign policy, but did so differently during World War II and in its aftermath. As a state in the midst of a brutal war, the United States first used nuclear weapons to escalate the conflict and win the war against Japan. Within the typology advanced by this book, this is best characterized as aggression, although there are also ways in which US nuclear weapons facilitated compromise over the terms of Japanese surrender and independence from the Soviet Union in the final days of the war. In the aftermath of World War II, the United States did not face severe territorial threats and was rising in power. The United States placed 
nuclear weapons at the heart of its foreign policy in the immediate aftermath of World War II, using nuclear weapons to facilitate behaviors that combined expansion, aggression, and steadfastness, as well as bolstering its allies. Nuclear weapons allowed the United States to engage in a rapid conventional demobilization while pursuing an ambitious grand strategy: maintaining a forward posture, seeking to bolster existing allies and take on new ones, resisting and deterring Soviet encroachments, and going beyond a purely defensive model of containment in its dealings with the Soviet Union.

The theory thus receives validation, performing well in explaining these cases in absolute terms and relative to the alternative explanations. Chapter 5 also shows the theory's ability to shed light on the behavior of many (though not all) of the other states to have acquired nuclear weapons, and makes clear predictions for how potential future proliferators would behave if they were to acquire nuclear weapons. The empirical evidence validates the broader view of nuclear weapons envisaged by the theory of nuclear opportunism. Political and military elites have generally viewed nuclear weapons as tools that enable them to pursue and protect their preexisting political interests and ambitions. Nuclear weapons were employed pragmatically in the service of those political priorities.

\section{Avenues for Future Research}

The book opens a number of avenues for future research.

First, the argument made here is in many ways a simple one: states are viewed as unitary actors and only three binary variables (of which none incorporates features of the domestic politics of the state) are used to explain variation in outcomes. This is obviously a simplification of a much more complex reality. There may be ways to add additional explanatory power to the theory by adding additional complexity that future research could explore. For example, there may be ways to incorporate the role of individual leaders' ideas about nuclear weapons, a factor that-as discussed in chapter 5-clearly appears to be important in explaining the way in which Chinese leaders have thought about the utility of nuclear weapons. ${ }^{1}$ Similarly, norms about the acceptability of nuclear use have changed dramatically over the nuclear era and may have influenced the effects that nuclear weapons have had in different eras. ${ }^{2}$ Last, different domestic political arrangements may influence the effects that nuclear weapons have. For example, nuclear weapons may have different effects in cases where the military controls the state's nuclear weapons compared with states in which civilians retain control of nuclear weapons. ${ }^{3}$

Similarly, the theory ignores the possibility of strategic interaction, and particularly, the possibility that other states can take actions to reduce the benefits that states receive from acquiring nuclear weapons. As it stands, the 
theory is choice theoretic rather than game theoretic or strategic: according to the theory, states that acquire nuclear weapons make decisions about how to use nuclear weapons without considering the actions that other states may take. ${ }^{4}$ As discussed in chapter 1 , this is a justifiable simplification that should bias us against observing evidence of the effect of nuclear weapons (if other states can take actions to mitigate the effects that nuclear weapons have, we should be less likely to observe a change in foreign policy behavior at the point of nuclear acquisition). Nonetheless, it ignores a potentially important dynamic that future work could incorporate. In short, the theory described here provides a baseline that future research can add qualifications and nuance to in order to enhance its ability to explain the full range of variation we observe.

Second, there may be opportunities to generalize the argument made here. Do other military capabilities facilitate the same range of foreign policy behaviors as nuclear weapons? If not, what are the characteristics of military technologies that lead them to facilitate particular behaviors? Similarly, does the theory shed light on the way in which states respond to other endogenous increases (that is, increases that the state chooses to invest in) in their power and military capabilities? Both the typology and the theory may have broader applicability, and the extent to which the theory travels to other circumstances may have important insights for exactly what is special or unusual about nuclear weapons.

Finally, the research design that this study employed focused on the effects of nuclear weapons at the point of acquisition and offered only relatively brief evidence in each case to suggest that these effects have endured over time. This was justified given the lack of existing work on the question of how nuclear weapons affect state foreign policy, the research design advantages of focusing on the point of nuclear acquisition, and the fact that policymakers care particularly about the immediate effects of nuclear acquisition. Nonetheless, it represents an important opportunity for future research. It would be productive for future research to examine in more detail why and to what extent the effects of nuclear weapons do indeed endure over time, and what, if anything, can cause states to fundamentally reevaluate the way in which they use their nuclear weapons to support their foreign policy goals.

\section{Implications for Scholars}

The book offers a number of implications for scholars of international politics and nuclear weapons.

The argument made here offers a new way of thinking about nuclear weapons that is at odds with the dominant theory of the nuclear revolution, and thus contributes to a growing body of work challenging various aspects 
of the theory of the nuclear revolution. ${ }^{5}$ While the theory of the nuclear revolution offers a powerful explanation for the absence of great power war since 1945, the political judgment within it about how states respond to the security provided by nuclear weapons appears flawed. The theory of the nuclear revolution is correct that nuclear weapons are a revolutionary capability in terms of the destructive power that they offer to states, and that they are therefore a powerful deterrent against aggression. However, the theory of the nuclear revolution errs in its political judgment about how states respond to those capabilities. Nuclear weapons do not cause states to worry less about their own security, do not reduce states' inclination to compete vigorously with each other, and do not tamp down states' ambitions in international politics. Instead, states use nuclear weapons in service of their preexisting political goals, and nuclear weapons are often useful in pursuit of those goals. Statesmen appear to view nuclear weapons in a political, pragmatic, and opportunistic manner: nuclear weapons can facilitate a range of foreign policy behaviors, and states seek to take advantage of this to pursue their political goals.

This vision of nuclear weapons is in some ways both more and less revolutionary than that implied by the theory of the nuclear revolution. It is less revolutionary in that it suggests nuclear weapons transform international politics or the preferences of states to a lesser degree than advocates of the theory of the nuclear revolution believe. Instead, nuclear weapons are incorporated into the practice of international politics and are used by states to pursue the political goals and aspirations that they found attractive before nuclear acquisition. Politics remains king, even in a nuclear-armed world. In other ways, however, the theory of nuclear opportunism views nuclear weapons as more revolutionary than the theory of the nuclear revolution. Specifically, the theory of nuclear opportunism views nuclear weapons as having much broader political utility than the theory of the nuclear revolution suggests. While the theory of the nuclear revolution views nuclear weapons as being primarily useful for deterring nuclear attack or resisting nuclear coercion, the theory of nuclear opportunism views nuclear weapons as facilitating a wide range of foreign policy goals that a range of states may find attractive. Nuclear weapons, in short, may transform a state's foreign policy in a more profound way than the theory of the nuclear revolution anticipates, but transform international politics less than the theory of the nuclear revolution expects.

Similarly, the book therefore offers a way for scholars to make sense of the heterogeneity in the way in which states have responded to nuclear acquisition. This heterogeneity has largely been missed or assumed away by the theory of the nuclear revolution, which argues that nuclear weapons should have a consistent effect across all states because of the technological characteristics of the weapons which make nuclear weapons easy to hide and protect, hard to defend against, and enormously destructive. However, because 
states occupy profoundly different positions in international politics and have profoundly different political priorities, the ways in which nuclear acquisition affects the foreign policies of acquiring states vary tremendously. There has not been one nuclear revolution. Instead, each nuclear-armed state has discovered the revolutionary capabilities that nuclear weapons offer and used them to pursue its own interests: each state, in short, has experienced its own nuclear revolution. The typology and theory offered here allow scholars to identify and understand the different effects that nuclear weapons have, and thus to make sense of the variety and nuance that we see in the historical record. ${ }^{6}$

The argument also has implications for other scholarly debates about nuclear weapons.

First, the book has implications for debates about the causes of proliferation. In particular, it suggests we should expand our assessment of the range of states that may find nuclear weapons attractive. For example, since the end of the Cold War, it has become increasingly common for scholars to think of nuclear weapons as "weapons of the weak" or "the great equalizer," implying that nuclear weapons are only useful for conventionally weak states seeking to deter the United States. ${ }^{7}$ It is certainly true that conventionally weak states gain from the acquisition of nuclear weapons because of their limited conventional capabilities. But it is not just weak or "rogue" states that may find nuclear weapons attractive. Since the dawn of the nuclear age, powerful states have regularly sought and benefited from the acquisition of nuclear weapons. The typology and theory offered in this book shed light on why this is and why it may continue in the future. Nuclear weapons can facilitate foreign policy behaviors that conventionally powerful states are likely to find extremely attractive, such as expansion or the bolstering of allies. It should not, therefore, be surprising that states have sometimes seen nuclear weapons as "status symbols," or that powerful states have often sought to acquire them, or that conventionally powerful and nuclear-armed states today show little interest in relinquishing their nuclear arsenals. Nuclear weapons are not simply a relic of the Cold War, and many states today continue to find nuclear weapons useful for pursuing their goals in international politics.

However, if we expand our assessment of the states that may find nuclear acquisition attractive, the book also points to the reasons why few states have acquired nuclear weapons despite their utility. In particular, the book offers a theoretical foundation for scholarship that emphasizes the role of the United States in preventing proliferation to both allies and adversaries. ${ }^{8}$ The argument here provides a theoretical justification for why the United States would place significant priority on the goal of nonproliferation. While the theory of the nuclear revolution suggests that proliferation should not be especially concerning to the United States, ${ }^{9}$ the theory of nuclear opportunism recognizes that proliferation-whether to adversaries or to states with 
which the United States has alliances-has the potential to harm the interests of the United States. Indeed, it is US policymakers' recognition of the benefits that nuclear weapons offer to states that has led the United States to seek to prevent proliferation. Adversaries of the United States can use nuclear weapons in a variety of ways that would harm the interests of the United States: to facilitate aggression against the United States or its allies, to better resist challenges from the United States, or to bolster their own allies. Further, even allies of the United States can use nuclear weapons in a range of ways that are inimical to US interests: allies can use nuclear weapons to become more independent from the United States and thus harder for the United States to control, to engage in aggression, or to pursue other behaviors that may draw the United States into conflicts it would rather avoid. The argument here, therefore, provides a theoretical justification for the United States' relative consistency in pursuing nonproliferation, and the importance that nonproliferation has historically played within US grand strategy.

Second, the argument here in some way reinforces, but also challenges, the notion of the "stability-instability paradox." As traditionally conceived, the stability-instability paradox provides an addendum to the theory of the nuclear revolution. The paradox points out that the high levels of strategic stability created by mutual assured destruction may lead to reduced stability at lower levels: if escalation to nuclear war is unthinkable, it paradoxically becomes safer to engage in lower-level conflict. ${ }^{10}$ In some ways, the argument here is consistent with the paradox: mutual assured destruction is not necessarily an impediment to lower-level conflict because states do not respond to nuclear weapons in the way the theory of the nuclear revolution expects. However, the logic is different from that which underpins the stability-instability paradox: states can compete at lower levels even in the shadow of nuclear weapons in the same way that they compete in a nonnuclear world, because nuclear weapons do not fundamentally change the nature of international politics. In an anarchic system in which states have differing and competing interests, conflict is always possible, even if nuclear weapons make such conflict deeply dangerous. The low-level conflict and crises that we see between nuclear-armed states, and that the stabilityinstability paradox identifies as an anomaly for the theory of the nuclear revolution, may simply be standard international politics between states competing for influence, territory, and security.

Third, the argument here offers a way to move beyond debates about whether nuclear weapons are "useful" to states in international crises, and the simple dichotomy between whether nuclear weapons are useful for compellence and whether they are useful solely for deterrence. ${ }^{11}$ The argument offered here clearly views nuclear weapons as politically useful weapons, and thus is not consistent with arguments that view nuclear weapons as being of limited use to states beyond offering the ability to deter. ${ }^{12}$ However, 
the theory also offers a more complex interpretation of the role nuclear weapons play in both the instigation and the resolution of crises than that offered by scholars who argue that nuclear weapons offer states clear advantages in crises. ${ }^{13}$ By shifting the analytic focus to foreign policy, and demonstrating the different foreign policy behaviors that nuclear weapons can facilitate, the argument here shows the ways in which nuclear weapons may affect how crises occur and play out in complex ways. For example, nuclear weapons have may have encouraged Britain to instigate crises that it was not well equipped to prevail in. Such a position would be hard to capture in a simple debate over whether nuclear weapons are helpful in crises.

Similarly, the argument here allows analysts to make sense of episodes that contain elements of both deterrence and compellence. For example, the way in which nuclear weapons facilitated US behavior in the postwar period is hard to capture within the compellence-deterrence dichotomy. Was the US decision to extend nuclear deterrence to states in Europe, Asia, and Australasia an effort to deter attacks against these allies? An effort to compel adversaries of these states to back down? An effort to deter allies from acquiring their own nuclear weapons? An effort to compel others to accept US dominance of the postwar world order? By focusing on the ways in which nuclear weapons facilitate particular behaviors, rather than compellence or deterrence, the argument here allows for a more nuanced assessment of the ways in which states use nuclear weapons to achieve their goals in international politics.

Fourth, the analysis demonstrates the importance of looking beyond the possession of nuclear weapons in understanding their political effects. Instead, it is the state's nuclear posture that determines the technological threshold at which nuclear weapons begin to affect state calculations about foreign policy. For example, although Britain first tested a nuclear weapon in 1952, it was only with the acquisition of a deliverable capability in 1955 that nuclear weapons began to influence British foreign policy. Despite this, political scientists tend to emphasize a country's first nuclear test as indicating the point at which the effects of nuclear weapons should be observed. ${ }^{14}$ This approach may generate misleading inferences, because nuclear weapons may not necessarily begin to influence a state's foreign policy at the point at which a country first tests a device.

\section{Implications for Policymakers}

The argument also has implications for policymakers thinking about nuclear proliferation and disarmament.

First, substantial traction on the effects of nuclear weapons can be gained by using a more discriminating conceptual language. "Emboldenment" is a convenient catch-all term, but it conflates conceptually distinct behaviors and 
misses other effects that nuclear weapons may have. Policymakers throughout the nuclear age have often expressed broad and generic concerns about the emboldening effects of nuclear weapons, but have often failed to think in detail about the precise behaviors that nuclear weapons may facilitate. ${ }^{15}$ These distinctions are important because not all emboldening effects are equally concerning to policymakers. Both aggression and steadfastness may be considered emboldening effects, but, for example, a nuclear-armed Iran that displays greater steadfastness is likely less concerning to US policymakers than a nuclear-armed Iran that pursues aggression. The typology offered here provides policymakers with a conceptual language with which to more precisely specify the concerns associated with particular potential proliferants.

Second, the theory offers policymakers a tool with which to make an initial assessment of the relative likelihood of different outcomes that may occur if particular states acquire nuclear weapons. The theory suggests, for example, that different US allies might respond to nuclear acquisition in different ways that would have different implications for US foreign policy. The theory suggests, for example, that the United States should be more worried by South Korea acquiring nuclear weapons than by Japan doing so. Similarly, the theory suggests that Iranian nuclear acquisition is more likely to lead to certain behaviors (such as bolstering of allies) than others (such as aggression). This is not to suggest that policymakers should not prepare for the possibility of Iranian aggression in the aftermath of nuclear acquisitionpolicymakers correctly prepare for a wide range of unlikely contingencies. Nonetheless, the theory has the potential to guide policymakers as they assess which outcomes are more likely, and help policymakers as they decide how to dedicate finite military and political resources to different contingencies. In this way, the theory can potentially help to refine, adjust, or provide a more solid intellectual foundation for policymakers' prior beliefs about the likelihood of different outcomes in a given case of proliferation.

Finally, the argument suggests that making substantial progress toward nuclear disarmament is likely to be difficult, and sheds light on the limited progress that the nuclear-armed states have made toward that goal. If nuclear weapons were merely vestiges of the Cold War, or if states simply wanted to possess nuclear weapons out of a misplaced belief that nuclear weapons confer great power status, then nuclear abolition would seem an achievable task: statesmen would simply need to be educated about the disutility of nuclear weapons. This book suggests, by contrast, that states that acquire nuclear weapons view them as useful for achieving foreign policy goals that they deem important and do in fact use nuclear weapons to facilitate a wide range of foreign policy behaviors. If so, nuclear-armed states will generally be less inclined to relinquish an important source of political power. Just as states do not typically give up other tools with which they can achieve their foreign policy goals-their militaries, intelligence services, 
diplomatic corps, and so on-nuclear-armed states will also be generally disinclined to give up their nuclear weapons. The argument of this book is that nuclear weapons facilitate foreign policy behaviors that a range of states find attractive, and help states achieve foreign policy goals that they value. If so, nuclear weapons are likely here to stay. Managing the risks that they pose will continue to be a central challenge for policymakers for some time to come. 
